Please note:

This is the author's version of the manuscript accepted for publication in the Journal of Constructivist Psychology. Changes resulting from the publishing process, namely editing, corrections, final formatting for printed or online publication, and other modifications resulting from quality control procedures, may have been subsequently added.

The published version can be found in:

Meira, L., Salgado, J. Sousa, I., Ribeiro, A., \& Gonçalves, M. (2017, E Pub ahead of print). Psychological Change in Everyday Life: An Exploratory Study. Journal of Constructivist Psychology. DOI: 10.1080/10720537.2017.1304300.

http://dx.doi.org/10.1080/10720537.2017.1304300 


\title{
Psychological change in everyday life: An exploratory study
}

\author{
Liliana Meira ${ }^{1}$, João Salgado ${ }^{1}$, Inês Sousa ${ }^{2}$, António Ribeiro $^{3}$, \& Miguel M. \\ Gonçalves ${ }^{3}$
}

${ }^{1}$ University Institute of Maia - ISMAI \& Center for Psychology at University of Porto, Portugal

${ }^{2}$ Department of Mathematics and Applications, University of Minho, Portugal

${ }^{3}$ Psychology Research Centre, School of Psychology, University of Minho, Portugal

Correspondence concerning this article should be addressed to Miguel M. Gonçalves, School of Psychology, University of Minho, 4710-057, Braga, Portugal. Telephone: 00351 253604220 / 253604683.Fax: 00351 253604224.mgoncalves@psi.uminho.pt

Acknowledgements:

This study was partially conducted at Psychology Research Centre (UID/PSI/01662/2013), University of Minho, supported by the Portuguese Foundation for Science and Technology and the Portuguese Ministry of Science, Technology and Higher Education through national funds, and co-financed by FEDER through COMPETE2020 under the PT2020 Partnership Agreement (POCI-01-0145-FEDER-007653). 


\begin{abstract}
The innovative moments model was used in a pilot study that aimed to explore the change processes involved in everyday change outside psychotherapy. According to this model, the emergence and development of innovative moments (IMs) as exceptions to a problematic pattern are closely associated with psychological change. A longitudinal design covering four months of interviews was implemented with 13 adults who were coping with significant personal problems without clinical psychopathological complaints. Semistructured interviews were used to explore participants' personal accounts of their problems, and change was assessed using a scaling task at the end of the study. A total of 114 interviews were analyzed using the Innovative Moments Coding System. A general linear model showed that higher levels of change were associated with higher proportions of complex IMs over time. Moreover, lower levels of change were associated with an increase in elementary IMs. These results support the idea that successful psychological change in everyday life shares similarities with the change pattern found in psychotherapy using the innovative moments model.
\end{abstract}

Keywords: Psychological change; everyday problem resolution; innovative moments; Innovative Moments Coding System 
Running head: PSYCHOLOGICAL CHANGE IN EVERYDAY LIFE

The way people change in their everyday lives, without professional help from a psychotherapist or a counselor can be informative of human change processes in general and also shed light on what occurs in psychotherapy. This study aims to explore how participants change as they cope with difficult life events without professional support, using their natural resources to promote change. Along these lines, several studies on positive change following traumatic stressful life events (Helgeson, Reynolds, \& Tomich, 2006; Linley \& Josephs, 2004, 2011; Park, 2010) or daily stressors (Abraham \& Stein, 2015; Gianakis \& Carey, 2011; Higginson \& Mansell, 2008; Losavio et al., 2011) aimed "to increase our understanding of naturally occurring change including the facilitators of this change" (Gianakis \& Carey, 2011, p. 442), and suggested that understanding everyday natural functioning can highlight how psychological change is facilitated by psychotherapy (Marken \& Carey, 2015).

Research on post-traumatic growth (Linley \& Joseph, 2004, 2011; Park, 2010), and stress-related growth (Helgeson et al., 2006, Losavio et al., 2011) suggests that traumatic, or even stressful events from the daily routine, challenge people's underlying assumptions about themselves and the world, compelling them to search for new meanings. Moreover, this achievement of new meanings is associated with positive change following difficult life events (Helgeson et al., 2006). Linley and Joseph (2011), for example, completed a study that aimed to assess whether there were differences among people's process of searching for new meanings, their achievement of new meanings following adverse life events and the association of this achievement with positive and negative changes as result of these experiences. They found that achievement of new meanings was associated with increased positive changes while the process of searching for new meanings was not associated with positive changes by itself. On the contrary, searching for meaning by itself was related to higher levels of negative change. For positive change to occur, it is necessary that a person 
engage in cognitive processing that will allow new meanings to be achieved and consolidated.

Change in people who had naturally recovered from different types of difficult life events, without psychotherapeutic help, have also been studied by Higginson and Mansell (2008) and Gianakis and Carey (2011). The overall result of both studies highlighted three common themes in the participants' self-reports about their change process. First, participants were aware of change as moving toward a new sense of identity or restoring a previous positive functional state, and they perceived their old and the new selves after recovery, which resulted in seeing themselves as changed people. Second, change was often perceived as a gradual and continuous process, although it could also be observed as the result of sudden insight. Finally, change was described as a result of reflexive processes characterized by increased insight and meaning reorganization specifically related to critical experiences associated with strong emotional arousal (Gianakis \& Carey, 2011; Higginson \& Mansell, 2008). Friedlander, Lee, and Bernardi (2013) analyzed pivotal life experiences with a positive value in life, and found that the event that precipitated the difficulty was a negative one or a challenging transition that led to a process of self-transformation. Moreover, they observed that the process of transforming these challenging or problematic life conditions into valuable experiences was associated with participants' personal accounts and were similar to those found in successful psychotherapy.

These studies on psychological change following difficult, or even traumatic life events, have provided valuable insights about the processes of human change amid struggle with difficult life experiences. Nevertheless, to the best of our knowledge, all empirical studies have relied mostly on a retrospective design to assess psychological change processes via the recollection of and the reflection on previous life events. As such, these studies have 
not observed psychological change as it unfolds, as people struggle with daily challenging events, which is one of the aims of the present study.

Recently, Gonçalves and colleagues (Gonçalves, Ribeiro, Mendes, Matos, \& Santos, 2011; Gonçalves et al., 2016) developed a coding system that tracks innovative moments (IMs) in psychotherapy to capture how change unfolds throughout treatment. IMs are defined as exceptions to a problematic pattern of meaning that motivate a client to seek therapy. This theoretical framework assumes that in psychopathology, the client's meaningmaking system is frozen in a redundant pattern, which leads her/him to act, think, feel and relate with others in repetitive ways that do not allow the problems to be solved. When IMs start to emerge, the redundant pattern is challenged and new meanings emerged (in the form of actions, thoughts, new pattern of relationship, and so on). Thus, IMs are new ways of acting, feeling, and thinking - ways that are alternative to the problematic pattern of meaning. This method of analysis of psychotherapy change has been applied to a wide diversity of problems (e.g., depression, prolonged grief, wife abuse) and therapeutic models, such as narrative therapy (Matos, Santos, Gonçalves, \& Martins, 2009; Gonçalves, Ribeiro, Silva, Mendes, \& Sousa, 2016), emotion-focused therapy (Mendes et al., 2010), clientcentered therapy (Gonçalves et al., 2012), constructivist therapy (Alves et al., 2014), and cognitive-behavior therapy (Gonçalves et al., 2015). From these studies, several systematic findings emerged: (1) IMs occur more in recovered than in unchanged cases; (2) IMs emerge in five different types - three elementary types (action, reflection, protest) and two complex types (reconceptualization and performing change) (see Table 2 in the Measures section for more details); (3) Elementary IMs are typical in the first and middle phases of therapy, while complex ones are typical of middle and late phases; and (4) Complex IMs almost do not emerge in unchanged cases. In sum, the innovative moments model of change suggests that elementary IMs are the most basic indicators of psychological change and are identified by 
the presence of new thoughts, feelings, and behaviors that are distinct from the initial problematic pattern of meaning. Reconceptualization IMs tend to emerge in recovered clients from intermediate sessions onward and to increase and evolve until the therapy ceases. These IMs have two primary features that promote and sustain change: a contrast between the initial problematic pattern of meaning and the new one; and the awareness of how this transformation between the former and the new meaning pattern emerged (Gonçalves \& Ribeiro, 2012). Moreover, reconceptualization IMs involves an agentic position of the self because the contrast was produced by something that the person did (or thought, or felt). Finally, following the emergence of reconceptualization IMs, performing change IMs -- i.e., actions that show commitment to new life projects -- allows the client to project the changes into the future (Cunha et al., 2012, Gonçalves et al., 2014; Gonçalves \& Ribeiro, 2012).

The innovative moments perspective on psychological change offers an empirical model of change in psychotherapy and a methodological procedure that allows the assessment of change as it emerges over time (Gonçalves et al., 2012). The model, therefore, may also be helpful to explore changes in everyday life. In the present study, our primary goal was to conduct an exploratory study on natural change processes using the IMs model to analyze change. Moreover, trying to avoid a central limitation of former studies (Gianakis \& Carey, 2011; Higginson \& Mansell, 2008; Linley and Joseph, 2011) on daily life change (their retrospective design), we developed a 4-month longitudinal design.

Two main research questions organize the present study: (1) Do participants produce IMs in everyday life change processes? (2) Are the patterns of change similar or different from those that occur in psychotherapy? That is, do participants who change more produce more complex IMs? We hypothesize that participants who change more have a higher presence of IMs, particularly complex IMs (reconceptualization and performing change 
Running head: PSYCHOLOGICAL CHANGE IN EVERYDAY LIFE

IMs). We have no expectation regarding elementary IMs (action, reflection, and protest IMs).

\section{Method}

\section{Participants}

The participants were Portuguese volunteers recruited after we publicized the study via e-mail, posters, and a public announcement at two university campuses and their surrounding communities. The study was promoted as a research project investigating personal change. The selection criteria for the study included participants who (1) were at least 18 years old, (2) were not attending psychotherapy services, (3) were able to identify and disclose a significant life problem, (4) were able to participate in a 4-month longitudinal study, and (5) did not present significant psychopathological symptoms at the beginning of the study, as measured by the General Symptom Index of the Brief Symptom Inventory (see more details in the Measures section).

A total of 33 participants were initially involved in this study; however, 10 participants were excluded because they were unable to fulfill one or more of the inclusion criteria. Participants who presented clinically significant emotional disturbance at the time of the first interview were referred to community psychological services. Among the 23 participants selected, ten dropped out during the study. All participants provided their written, signed consent, and no compensation was offered for their adherence to the longitudinal design.

Overall, 13 participants completed the study, six men and seven women aged 20 to 54 years old $(M=31.54)$, all Caucasian. In terms of marital status, eight were single, two were married, and three were divorced. Regarding the academic qualifications, one had a secondary education, six were working toward a university degree, five were university 
Running head: PSYCHOLOGICAL CHANGE IN EVERYDAY LIFE

graduates, and one had a master's degree. None of the participants sought professional help during the study. Table 1 displays a brief characterization of the types of problems presented by each participant as well as the number of interviews completed during the 4-month study.

[Insert Table 1]

\section{Measures}

The Brief Symptom Inventory (BSI) (Derogatis, 1982; Portuguese version by Canavarro, 1999) is a short version of the Symptom Checklist (SCL-90-R) (Derogatis, 1977) and was used for assessing psychopathological symptoms, only for sampling purposes. The BSI is a 53-item questionnaire that assess nine dimensions of psychopathological symptoms - somatization, interpersonal sensitivity, obsessions and compulsions, depression, anxiety, hostility, phobic anxiety, paranoid ideation, and psychoticism—and three global indexes, i.e., the general symptom index (GSI), which reveals the overall level of psychopathological symptoms. The Portuguese adaptation by Canavarro (1999) showed overall high reliabilities, with Cronbach's $\alpha$ falling between .7 and .8 ; an exception was phobic anxiety and psychoticism scales, with Cronbach's $\alpha$ slightly lower than .7. In this study, we specifically used the GSI from the general population $(M=.835, S D=.48)$ to establish a cut-off of 1.32 (i.e., $M+1 S D$ ), which allowed identifying participants with clinically significant symptoms.

An adaptation of de Shazer's scaling task (1990) was used to evaluate the change from participants' perspective, completed in the last interview. The participants were asked to rate the dominance of the initial problems in their life using a 10-point scale, in which 1 signifies total dysfunction and 10 signifies optimal functioning. The two ratings were 
Running head: PSYCHOLOGICAL CHANGE IN EVERYDAY LIFE

requested at the final interview, one for the initial (retrospectively) and one for the last interview.

A semi-structured interview was used to collect the data. Three protocols of semistructured interviews were constructed: one for the first interview, a second for the intermediate follow-up interviews, and a third for the last interview.

The first interview involved communicating to participants information regarding the study's general objectives (i.e., to study how people address daily difficulties) and procedures. The interviewer proceeded with open-ended questions to explore the narratives about the problematic experiences, specifically the subject or theme of the problem, contexts, characters, episodic examples, actions, thoughts and feelings, impact on everyday life domains, and description of efforts made to solve the problem.

The intermediate follow-up interviews focused on how the problem's impact had changed since the previous interview. The questions aimed to collect the most complete narratives relative to the problem since the last encounter, including the subject or theme, contexts, characters, episodic examples, actions, thoughts and feelings on everyday life domains, and description of the efforts made to solve the problem.

The last interview, in addition to the topics of the intermediate interviews, also involved questions on the evaluation of the entire set of interviews, asking for a revision of what had occurred during this period from the participants' perspective. Moreover, in the interview, questions were asked concerning participants' future plans for handling their former and present difficulties. This interview protocol was similar to the one employed by Gianakis and Carey (2011) and Higginson and Mansell (2008).

The Innovative Moments Coding System - IMCS (Gonçalves et al., 2011) is a qualitative procedure used for tracking the proportion of five types of IMs: action, reflection, protest, reconceptualization, and performing change (Table 2). The proportion is calculated 
per interview, which corresponds to the amount of time that each participant spends elaborating on each IM type. The sum of the five types of IMs allows having a global measure of IMs. The sum of the proportion of action, reflection and protest IMs allows the calculation of elementary IMs, whereas the sum of the proportion of reconceptualization and performing change allows the calculation of complex IMs. The reliability of the IMCS has been demonstrated in previous studies, with Cohen's kappa ranging from .86 to .97 (Gonçalves et al., 2011; Mendes et al., 2010; Alves et al., 2014), which indicates a strong, reliable agreement between coders (>.75) (Hill \& Lambert 2004; Hill et al., 2005). The reliability for this study is displayed in the Procedures section.

[Insert Table 2]

\section{Procedures}

\section{Data collection}

The three semi-structured interviews — first, intermediate, and final—were conducted at both campuses where the study was announced, at participants' home or workplace, or at a community center, always in a private, quiet setting. The interviews were conducted at 2 - to 3-week intervals over four months and were performed by one interviewer (first author), who was a female doctoral student with six years of training in clinical psychology and cognitive behavioral psychotherapy. During all interviews, the interviewer assumed a nontechnical position while asking open-ended questions regarding the status of the problematic situation identified by the participant in the initial meeting. The interviewer did not intentionally interfere with participants' spontaneous efforts to solve their problems (e.g., by making suggestions or giving advice); she only collected the most comprehensive account of how they were living with the initial difficulty to which they referred. Each of the 
interviews lasted approximately $30-60 \mathrm{~min}$ and was audio recorded. The BSI was administered at the end of the first interview, and the scaling task was applied at the last interview. We did not use the BSI at the last interview because the participants recruited had a low score in the BSI, which led to their non-clinical status.

\section{Data analysis}

In this study, a total of 114 interviews, with 13 participants, were coded using the IMCS. For reliability assessment, Coder 1 (first author) coded 100\% of the sample (114 interviews), and Coder 2 independently coded $31.6 \%$ of the sample (36 interviews), corresponding to the interviews with four participants (P3, P6, P9, P11). Coder 2 was unaware of the outcomes in terms of the change in these four participants at the end of the study. Both coders were previously trained in the coding procedures and directly supervised by its original authors.

Coding IMs involved the following three steps: (1) the coders' consensual definition of the problems shared by the participants, (2) the identification of IMs directly from the audiotaped interviews, computing the time (seconds) spent on each one, and (3) the categorization of each IM by type.

(1) Consensual definition of the participants' problems: For each participant, a consensual list of problems was presented at the beginning of the coding process by each coder, taking into account the problems shared by each participant. Each coder first prepared an independent list of problems, and subsequently, the two lists were discussed by both coders until a consensual final list of problems was achieved. This list oriented the identification and categorization of IMs throughout the interviews as exceptions to the listed problems.

(2) Identification of IMs throughout the audio recordings: After the consensual definition of each participant's list of problems was established, all interviews were coded 
independently for the presence of IMs by each coder following its sequential order. Each IM's onset and offset were identified and computed in seconds directly from the audio recordings.

(3) IMs' categorization in terms of type and proportion: After the IMs were identified, they were independently classified into types by both coders. In this study, we have two measures of IMs: the proportion of elementary IMs (action, reflection and protest), and the proportion of complex IMs (reconceptualization and performing change IMs).

In terms of reliability calculation, the percentage of agreement between the two coders regarding the overall proportion of IMs was computed as the number of overlapping seconds identified by both coders as corresponding to IMs; then, they were divided by the total amount of time of the interview. To assess the agreement between coders regarding the five types of IMs, Cohen's kappa was computed (see additional details regarding the IMCS in Gonçalves et al. [2011]). The degree of agreement between the two coders on the overall IMs proportion was $97.64 \%$, which means that approximately $98 \%$ of the proportion of IMs identified was common for the two coders, independent of the type. The reliability of the type of IMs was .92, as assessed by Cohen's kappa. These values represented a very good agreement between coders. After this phase of the reliability assessment of the IMCS, Coder 1 (first author) completed the coding of the remaining interviews with the IMCS.

\section{Results}

\section{Evolution of IMs in the 4-month period}

To study the evolution of IMs in the 4-month period, we used a general linear model (GLM), which allowed us to compare the evolution of IMs according to participants' change. Thus, the GLM analysis was computed with the proportion of IMs (elementary and complex IMs) as the response variable and time in the study, change (scaling task), and the 
interaction between time and change as explanatory variables. This type of analysis allowed us to identify change patterns over time (Agresti, 2002).

In this analysis, the probability of "non-occurrence of an IM" or the "occurrence of a certain type of IM" was illustrated as a binary response variable 0/1. This probability was treated as a random variable with a Bernoulli distribution, and the primary goal was to infer the probability parameter associated with this distribution. A generalized linear mixed effects model (Agresti, 2002) was used, integrating a subject-specific random effect to consider the variability among participants. A correlation between measurements from the same participant was expected. Thus, we estimated the following:

$$
\mathrm{P} \text { (occurrence of an IM of a certain type-explanatory variables) }=\mu \text {, }
$$

where the explanatory variables have a linear effect on the probability through a link function so that

$$
\mu=(\exp (\eta)) /(1+\exp (\eta))
$$

where $\eta$ is the logarithm of the odds ratio between the occurrence and the non-occurrence of an IM. More specifically,

$$
\eta=\log (\mu /(1-\mu))
$$

The explanatory variables were considered as

$$
\eta=\beta \times X
$$

where vector $\mathrm{X}$ represents all of the significant explanatory variables, and $\beta$ corresponds to the vector of the parameters to be estimated.

More specifically,

$$
\eta=\beta 0+\beta 1 \times \text { interview }+\beta 2 \times C+\beta 3 \times \text { interview } \times C,
$$

where $\beta 1 \times$ interview is the effect of time (evolution from the first interview to the last interview), $\beta 2 \times \mathrm{C}$ is the level of change (that is, the difference between the evaluation of the 
difficulties at the first interview and the last interview), and $\beta 3 \times$ interview $\times \mathrm{C}$ corresponds to the interaction between time and change.

The evaluation of the levels of change in participants had a mean of 3 points $(S D=$ $.91)$ in the first interview and a mean of 6.69 points $(S D=2.4)$ in the last interview. Table 3 shows the results regarding the levels of change in participants in the first and last interviews. This means that on average, participants evaluated the difficulties at the beginning as worse than those at the end of the study.

[Insert Table 3]

The results showed that the parameter change had no significant effect on the probability of the emergence of elementary IMs $(p=.924)$. The results regarding the parameter time showed significant positive effects on the probability of occurrence of elementary IMs $(p=.006)$. This parameter explained only $3.5 \%\left(R^{2}=.035\right)$ of the variance in elementary IMs over time. The results regarding the parameter interaction between time and change showed a significant positive effect on the probability of occurrence of elementary IMs $(p<.0001)$. Again, the variance explained was low $\left(R^{2}=.039\right)$. The results also showed that the participants exhibited no significant differences $(p=.39)$ in the proportion of elementary IMs at the beginning of the study.

Figure 1 shows the evolution of the likelihood of elementary IMs over time. The different gradient lines represent the evolution of elementary IMs probabilities. To illustrate the evolution, we selected two extreme cases [P9 $($ diff $=0)$, P5 $($ diff $=7)]$ and two intermediate cases [P3 and P10 (diff =4)] on the scaling task (that is, P9 had no change, while P5 had the highest change, i.e., seven points). All other participants fell in between the extreme participants. The general pattern of the evolution of elementary IMs showed that 
participants with higher levels of change (e.g., P5, diff =7) followed a steady pattern of a decrease in the probability of these IMs over time, whereas participants with lower levels of change (e.g., P9, diff $=0$ ) showed a general steady pattern of an increase in the evolution of elementary IMs' probabilities over time.

[Insert Figure 1]

The same model was used for complex IMs. The results showed that the parameter change had a significant positive impact on this group's probability of occurrence of IMs ( $p$ $=.041$ ), with this parameter explaining $70 \%$ of the variance of the complex IMs proportion $\left(R^{2}=.70\right)$. There was also a significant positive effect on the probability of emergence of the complex IMs on the parameter time $(p<.0001)$, with this parameter accounting for $73 \%\left(R^{2}\right.$ $=.73)$ of the variance in complex IMs over time. Finally, the parameter interaction between time and change showed significant positive effects $(p=.0001)$ on the probability of occurrence of complex IMs, considering $72 \%$ of the variance in the proportion of this group of IMs $\left(R^{2}=.719\right)$ over time. The results also showed some differences among participants regarding the proportion of the complex IMs at the first interview; nevertheless, this difference was only marginally significant $(p=.07)$.

Figure 2 illustrates the evolution of the likelihood of complex IMs over time. The different gradient lines represent the evolution of complex IM probabilities, once again, between two participants with extreme differences in levels of change [P9 (diff $=0$ ), P5 (diff $=7)]$ and two participants with intermediate levels of change [P3 and P10 (diff =4)]) on the scaling task. All other participants fell in between the extreme participants. As shown in this figure, until interview 6, the probabilities of complex IMs occurrence were similar for all participants. However, from interview 6 until the end of the study, although all participants 
Running head: PSYCHOLOGICAL CHANGE IN EVERYDAY LIFE

had started to exhibit higher rates of increase, the highest rate of increase was achieved by participants with higher levels of change (e.g., P5, diff =7). Participants with lower levels of change (e.g., P9, diff = 0) were those with the lowest rates of probability of complex IM occurrence over time.

[Insert Figure 2]

\section{Discussion}

In this study, we aimed to understand how change unfolds in everyday life according to the innovative moments model, specifically, to check whether IMs emerge in everyday life, without psychotherapy, and to analyze whether there were differences between elementary and complex IMs occurring over time among participants with different levels of change.

Regarding the first research goal, our findings showed that the IMCS is a suitable tool for studying psychological change as it unfolds in everyday life. The IMs overall proportion achieved $21.41 \%$ of the total time of the interviews, which means that this amount of time was spent in elaborating innovation on the problematic pattern of meaning. These results were similar to what was found in psychotherapeutic samples (Alves et al., 2014; Gonçalves et al., 2012; Matos et al., 2009; Mendes et al., 2010).

Our results also showed that the emergence of elementary IMs (action, reflection, and protest IMs) in the study was not predicted by time, change or the interaction between time and change. These findings were also consistent with the ones from previous studies in psychotherapy and from the overall IMs research (Cunha et al., 2012; Gonçalves \& Ribeiro, 2012), which suggests that elementary IMs seem to play a less fundamental role in psychological change. Nevertheless, in our study, these more elementary types of IMs (new 
Running head: PSYCHOLOGICAL CHANGE IN EVERYDAY LIFE

thoughts, feelings, and behaviors distinct from the problematic ones) seemed to be associated with the maintenance of difficulties, as they increased in participants with lower levels of change. We speculated that elementary IMs were used as a form of coping with the inability to change. Thus, elementary IMs could be a type of compromise solution: the person produces an innovation that does not threaten problematic personal stability but simultaneously is incapable of producing long-lasting change. This interesting pattern is different from what was found in psychotherapy, in which these IMs seem to be precursors of complex IMs in good outcome cases (Gonçalves \& Ribeiro, 2012).

In contrast to elementary IMs, time and interaction between time and change predicted complex IMs unfolding over time, that is, reconceptualization and performing change IMs. More specifically, our findings showed that the proportion of complex IMs increased over time primarily in participants with higher levels of change. These results, as predicted by the innovative moments model (Gonçalves et al., 2014; Gonçalves \& Ribeiro, 2012), further supported the key role of more complex IMs in psychological change (e.g., Alves et al., 2014; Cunha et al., 2012; Gonçalves \& Ribeiro, 2012), that is, more effective psychological change in everyday life seems to be associated with more complex IMs. This means that people who evaluated themselves as changing during the period of the study were more able to create contrasts between the initial problem and a new more adjusted position, were able to describe what allowed them to operate this transformation (these two components are part of reconceptualization IMs) and were also able to talk about new life expectations and future projects (through performing change IMs).

Our findings also have several similarities with previous research on natural psychological change following difficult live events (Friedlander et al., 2013; Gianakis \& Carey, 2011; Higginson \& Mansell, 2008). According to these studies, change in everyday life tends to be associated with reflexive processes characterized by increased insight, 
meaning reorganization and feelings of self-control, activated by critical events (Friedlander et al., 2013; Gianakis \& Carey, 2011). It is clear from our data that successful change tends to be associated with higher levels of complexity in reflexive processes (associated with reconceptualization and performing change IMs). Therefore, psychological change in everyday life may depend not only on being able to think, act, and feel differently about the difficulties — present in more elementary IMs (action, reflection, and protest IMs) — but on the ability to achieve a metacognitive perspective of oneself through more complex type of meaning making, i.e., complex reflexive processes (Losavio et al., 2011; Park, 2010).

Moreover, our results suggested that without this evolution in the level of complexity of IMs unfolding over time, these more elementary IMs (i.e., action, reflection, and protest IMs) might be related to the maintenance of difficulties. These results are in line with previous findings that show that searching for meaning by itself is not associated with positive change; the person must engage in more complex reflexive processing that will allow new meanings to emerge (Linley \& Joseph, 2011). This is an interesting line of research for the future: how elementary forms of innovation may lead a person to become "frozen" in the same pattern, becoming entrapped in it. This is perhaps similar to what a strategic therapist described as "more of the same", i.e., an ironic pattern in which the more the person has the feeling that is creating novelty and tries to solve the difficulties, the more the problematic pattern is consolidated (see Fraser \& Salovey, 2007; Watzlawick, Weakland, \& Fish, 1974).

This study has several limitations. First, the use of regular interviewing throughout the 4-month procedure may in fact, even if not intentionally, have interfered with people's spontaneous change processes. Although the interviewer tried to assume a "non-therapeutic" position throughout the interviews, research on psychotherapy shows that the relational dimensions of treatment are therapeutic in themselves (Wampold \& Imel, 2015). The simple 
Running head: PSYCHOLOGICAL CHANGE IN EVERYDAY LIFE

fact that some of these participants could have felt socially isolated and unable to share their difficulties with their family or friends, may have created an opportunity for change as they were sharing their inner thoughts and feelings with an interviewer who was attentive and friendly. Nevertheless, to our knowledge, this was the first study to approach psychological change in everyday life using a longitudinal design. A second limitation was the retrospective evaluation of the level of difficulties at the beginning of the study. Future studies should use measures of change along the way. The major problem is that traditional measures used in psychotherapy are not sensitive to the changes that occur in studies such as this, as there is an absence of psychopathological symptoms. The fact that change was evaluated from the perspective of the participants and IMs were evaluated from an independent observer reduces the possibility of a "halo effect" between the measures. Finally, this is just an exploratory study as the sample is small and highly heterogeneous in terms of the difficulties that participants shared, therefore, future research should analyze larger samples. 


\section{References}

Abraham, K. M., \& Stein, C. H. (2015). Stress-related personal growth among emerging adults whose mothers have been diagnosed with mental illness. Psychiatric Reabilitation Journal, 38, 227-233. doi: 10.1037/prj0000128

Agresti, A. (2002). Categorial data analysis (2nd edition). NY: Wiley.

Alves, D., Fernandez-Navarro, P., Baptista, J., Ribeiro, E., Sousa, I., \& Gonçalves, M. M. (2014). Innovative moments in grief therapy: The meaning reconstruction approach and the processes of self-narrative transformation. Psychotherapy Research, 24, 2541. doi:10.1080/10503307.2013.814927

Canavarro, M. C. (1999). Inventário de Sintomas Psicopatológicos: BSI. In M. R. Simões, M. M. Gonçalves, \& L. S. Almeida (Eds.), Testes e provas psicológicas em Portugal, vol. 2. Braga: APPORT

Cunha, C., Gonçalves, M. M., Hill, E. A., Mendes, I., Ribeiro, A. P., Sousa, I., Angues, L., \& Greenberg, L. S. (2012). Therapist interventions and client innovative moments in emotion-focused therapy for depression. Psychotherapy, 49, 536-548. doi: $10.1037 / \mathrm{a} 0028259$

de Shazer, S. (1991). Putting difference at work. NY: W. W. Norton \& Company. Fraser, J. S., \& Solovey, A. D. (2007). Second-order change: The golden thread that unifies effective treatments. Washington, DC: American Psychological Association.

Friedlander, M. L., Lee, H., \& Bernardi, S. (2013). Corrective experiences in everyday life: A qualitative investigation of transformative change. The Counseling Psychologist, 41, 453-479. doi:10.1177/0011000012439476

Gianakis, M., \& Carey, T. A. (2011). An interview study investigating experiences of psychological change without psychotherapy. Psychology and Psychotherapy: Theory, Research and Practice, 84, 442-457. doi:10.1111/j.2044-8341.2010.02002 
Gonçalves, M. M., Gabalda, I. C., Ribeiro, A. P., Pinheiro, P., Borges, R., Sousa, I., \& Stiles, W. B. (2014). The Innovative Moments Coding System and the Assimilation of Problematic Experiences Scale: A case study comparing two methods to track change in psychotherapy. Psychotherapy Research, 24, 442-455. doi:10.1080/10503307.2013.835080

Gonçalves, M. M., Mendes, I., Cruz, G., Ribeiro, A. P., Sousa, I., Angus, L., \& Greenberg, L. S. (2012). Innovative moments and change in client-centered therapy. Psychotherapy Research, 22, 389-401. doi:10.1080/10503307.2012.662605

Gonçalves, M. M., \& Ribeiro, A. (2012). Narrative processes of innovation and stability within the dialogical self. In H. J. M. Hermans \& T. Gieser (Eds.), Handbook of dialogical self theory (pp. 301-318). Cambridge, UK: Cambridge University Press

Gonçalves, M. M., Ribeiro A. P., Mendes, I., Alves, D., Silva, J., Rosa, C., Braga, C., Batista, J., Fernández-Navarro, P., \& Oliveira, J. T. (2016). Innovative moments, ambivalence and ambivalence resolution: Three narrative based coding systems. (Manuscript under preparation)

Gonçalves, M. M., Ribeiro, P. A., Mendes, I., Matos, M., \& Santos, A. (2011). Tracking novelties in psychotherapy process research: The Innovative Moments Coding System. Psychotherapy Research, 21, 497-509. doi:10.1080/10503307.2011.560207

Gonçalves, M. M., Ribeiro, A. P, Silva, J., Mendes, I., \& Sousa, I. (2016). Narrative innovations predict symptom improvement: Studying innovative moments in narrative therapy of depression. Psychotherapy Research, 4, 425-435. http://dx.doi.org/10.1080/10503307.2015.1035355

Gonçalves, M. M., Silva, J., Mendes, I., Rosa, C., Ribeiro, P. P., Baptista, J., Sousa, I., \& Silva, C. F. (2015). Narrative changes predict symptoms decrease in CBT for depression: An exploratory study. (Manuscript under preparation) 
Running head: PSYCHOLOGICAL CHANGE IN EVERYDAY LIFE

Helgeson, V. S., Reynolds, K. A., \& Tomich, P. L. (2006). A meta-analytic review of benefit finding and growth. Journal of Consulting and Clinical Psychology, 74, 797-816. doi:10.1037/0022-006X.74.5.797

Higginson, S., \& Mansell, W. (2008). What is the mechanism of psychological change? A qualitative analysis of six individuals who experienced personal change and recovery. Psychology and Psychotherapy: Theory, Research and Practice, 81, 309328. doi: $10.1348 / 147608308 \times 320125$

Hill, C. E., Knox, S., Thompson, B. J., Williams, E. N., Hess, S. A., \& Ladany, N. (2005). Consensual qualitative research: An update. Journal of Counseling Psycology, 52, 196-205. doi: 10.1037/0022-0167.52.2.196

Hill, C. E., \& Lambert, M. F. (2004). Methodological issues in studying psychotherapy processes and outcomes. In M. Lambert (Ed.), Bergin \& Garfield's handbook of psychotherapy and behavior change (5th ed.) (pp. 84-135). NY: John Wiley \& Sons.

Linley, P. A., \& Joseph, S. (2011). Meaning in life and posttraumatic growth. Journal of Loss and Trauma, 16, 150-159. doi:10.1080/15325024.2010.519287

Linley, P. A., \& Joseph, S. (2004). Positive change following trauma and adversity: A review. Journal of Traumatic Stress, 17, 11-21. doi: 0894-9867/04/0200-0011/1

Losavio, S. T., Cohen, L. H., Laurenceau, J-P., Dasch, K. B., Parrish, B. P., \& Park, C. L. (2011). Reports of stress-related growth from daily negative events. Journal of Social and Clinical Psychology, 30, 760-785. doi:10/1521/jscp.2011.30.7.760

Marken, R. S., \& Carey, T. A. (2015). Understanding the change process involved in solving psychological problems: A model-based approach to understanding how psychotherapy works. Clinical Psychology and Psychotherapy, 22, 580-590. doi:10.1002/ccp.1919 
Running head: PSYCHOLOGICAL CHANGE IN EVERYDAY LIFE

Matos, M., Santos, A., Gonçalves, M. M., \& Martins, C. (2009). Innovative moments and change in narrative therapy. Psychotherapy Research, 19, 68-80. doi:10.1080/10503300802430657

Mendes, I., Ribeiro, A. P., Angus, L., Greenberg, L. S., Sousa, I., \& Gonçalves, M. M. (2010). Narrative change in emotion-focused therapy. How is change constructed through the lens of the innovative moments coding system? Psychotherapy Research, 20, 692-701. doi:10.1080/10503307.2010.514960

Park, C. L. (2010). Making sense of meaning literature: An integrative review of meaning making and its effects on adjustment to stressful life events. Psychological Bulletin, 136, 257-301. doi:10.1037/a0018301

Watzlawick, P., Weakland, J., \& Fish. R. (1974). Change: Principles of problem formation and problem resolution. NY: Norton

Wampold, B. E., \& Imel, Z. E. (2015). The great psychotherapy debate: The evidence for what makes psychotherapy work ( $2^{\text {nd }}$ edition). NY: Routledge 
Running head: PSYCHOLOGICAL CHANGE IN EVERYDAY LIFE

Table 1

Participants' Types of Problems and Number of Interviews Completed

\begin{tabular}{lll}
\hline Participant & Number of & Types of problems \\
& interviews &
\end{tabular}

\begin{tabular}{|c|c|c|}
\hline P1 & 8 & $\begin{array}{l}\text { Difficulties in time management and overworking; social } \\
\text { withdrawal; and difficulties in addressing negative feelings and } \\
\text { thoughts regarding a recently ended intimate relationship. }\end{array}$ \\
\hline P2 & 8 & $\begin{array}{l}\text { Difficulties in managing daily routines and tasks; } \\
\text { discouragement towards academic assignments; and a lack of } \\
\text { academic performance. }\end{array}$ \\
\hline P3 & 9 & $\begin{array}{l}\text { Difficulties in achieving a vocational/professional definition, } \\
\text { which results in dissatisfaction, and an inability to adapt to the } \\
\text { workplace and the current professional task. Undecided } \\
\text { regarding an eventual choice for a self-sustaining lifestyle in } \\
\text { direct contact with nature. }\end{array}$ \\
\hline P4 & 8 & $\begin{array}{l}\text { Difficulties in planning and managing daily routines concerning } \\
\text { the writing and conclusion for the master's dissertation; and } \\
\text { social withdrawal. }\end{array}$ \\
\hline P5 & 10 & $\begin{array}{l}\text { Difficulties in readapting to her hometown after } 1.5 \text { years of } \\
\text { emigrating to another country; unemployment and financial } \\
\text { dependence on parents; and professional dissatisfaction. }\end{array}$ \\
\hline P6 & 10 & $\begin{array}{l}\text { Difficulties in social interaction and integration after one year of } \\
\text { sexual orientation definition; and fear of rejection by the peer }\end{array}$ \\
\hline
\end{tabular}


P7

P9

P11

P12

P13 general.

8 Difficulties in managing time, daily routine, and professional overwork; and difficulties in coordinating professional tasks with the status of a working student.

9 Emotional difficulties after a contentious divorce experience; social withdrawal; and feelings of loneliness.

8 Difficulties in managing time, daily routine, and sleep; low resistance to frustration and irritability; and difficulties with social interaction.

10 Difficulties in public speaking and social exposure; a lack of assertiveness when faced with social conflicts; a lack of academic performance; and family and marital problems.

9 Difficulties in constructing intimate relationships of trust after two contentious divorces; social isolation; and sadness.

9 Relationship difficulties with ex-husband after a contentious divorce; difficulties with accessing and interacting with her children, whose custody was given to the ex-husband; and management constraints on the execution of her master's thesis.

8 Difficulties in public speaking and social exposure; a lack of academic performance; and social anxiety. 
Running head: PSYCHOLOGICAL CHANGE IN EVERYDAY LIFE

Table 2

Innovative Moments Definition and Clinical Vignettes

\section{Examples}

\section{Contents}

(Problematic pattern of meaning: depression)

- New coping behaviors while

C: Yesterday, I went to the cinema for the first facing anticipated or existing time in months!

obstacles

- Effective resolution of unsolved

을 problems

- Active exploration of solutions

- Restoring autonomy and selfcontrol

- Searching for information regarding problems

\section{Creating distance from problems}

- Comprehension: Reconsidering

C: I realize that what I was doing was humanly

صِّ the causes of problems and impossible. I was pushing myself, and I never awareness of their effects allowed myself any free time. . . it's more

- New problem formulation natural and healthier to let go some of these

- Adaptive self-instruction and extra activities. 
Running head: PSYCHOLOGICAL CHANGE IN EVERYDAY LIFE

self-thought

- Intention to fight problems'

demands and references to self-

worth and feelings of well-being

\section{Centered on change}

- Therapeutic process: Reflecting on the therapeutic process

- Change process: Considering the process and strategies implemented to overcome problems and references of selfworth and feelings of well-being as consequences of change

- New positions: References to emergent identity versions induced by problems
C: I believe that our talks and sessions have proven to be fruitful. I felt like going back to old times; it was good. I felt good. Ifelt it was worth it. 


\section{Criticizing problems}

- Repositioning oneself toward

C: What am I becoming after all? Is this

problems

where I'm headed? Am I going to stagnate

here?

$\stackrel{\overrightarrow{0}}{0}$

Emergence of new positions

- Positions of assertiveness and

C: I'm an adult, and I'm responsible for my

empowerment

life, and I want to acknowledge these feelings,

and I'm going to let them out. I want to

experience life. I want to grow, and it feels

good to be in charge of my life. 
Reconceptualization IMs always

involve two dimensions:

- Description of the shift between two positions (i.e., past and

ֻี

- The process underlying the

C: You know ... when I was there at the museum, I thought to myself, "You really are different'. ... A year ago, you wouldn't be able to go to the supermarket. Ever since I started going out, I started feeling less depressed. . . . It is also related to our conversations and changing jobs. T: How did you get this idea of going to the museum?

C: I called my dad and told him that we're going out today.

T: This is new, isn't it?

C: Yes, it's like I tell you: I sense that I'm different. 
- Generalization into the future and other life dimensions of good outcomes

- Problematic experience as a resource in new situations

- Investment in new projects as a result of the process of change

- Investment in new relationships as a result of the process of change

- Performance of change: new skills

- Re-emergence of neglected or forgotten self-versions
T: You seem to have so many projects for the future now.

C: Yes, you're right. I want to do all of the things that were impossible for me to do while I was dominated by depression. I want to work again and to have time to enjoy my life with my children. I want to have friends again. The loss of all of the friendships in the past is something that still hurts me deeply. I want to have friends again, have people to talk to, share experiences, and feel engaged in my life again.

Note. Adapted with permission from Gonçalves, M. M., Ribeiro, P. A., Mendes, I., Matos, M., \& Santos, A. (2011). Tracking novelties in psychotherapy process research: The Innovative Moments Coding System. Psychotherapy Research, 21, 497-509. 
Running head: PSYCHOLOGICAL CHANGE IN EVERYDAY LIFE

Table 3

Participants' Levels of Change According to the Scaling Task at the First and Last Interview

\begin{tabular}{cccccccccccccc}
\hline Participant & P1 & P2 & P3 & P4 & P5 & P6 & P7 & P8 & P9 & P10 & P11 & P12 & P13 \\
\hline $\begin{array}{c}\text { First } \\
\text { interview } \\
\text { Last }\end{array}$ & 3 & 2 & 4 & 3 & 3 & 3 & 3 & 4 & 3 & 1 & 2 & 4 & 4 \\
interview & 8 & 8 & 8 & 8 & 10 & 8 & 8 & 7 & 3 & 5 & 3 & 5 & 6 \\
\hline
\end{tabular}




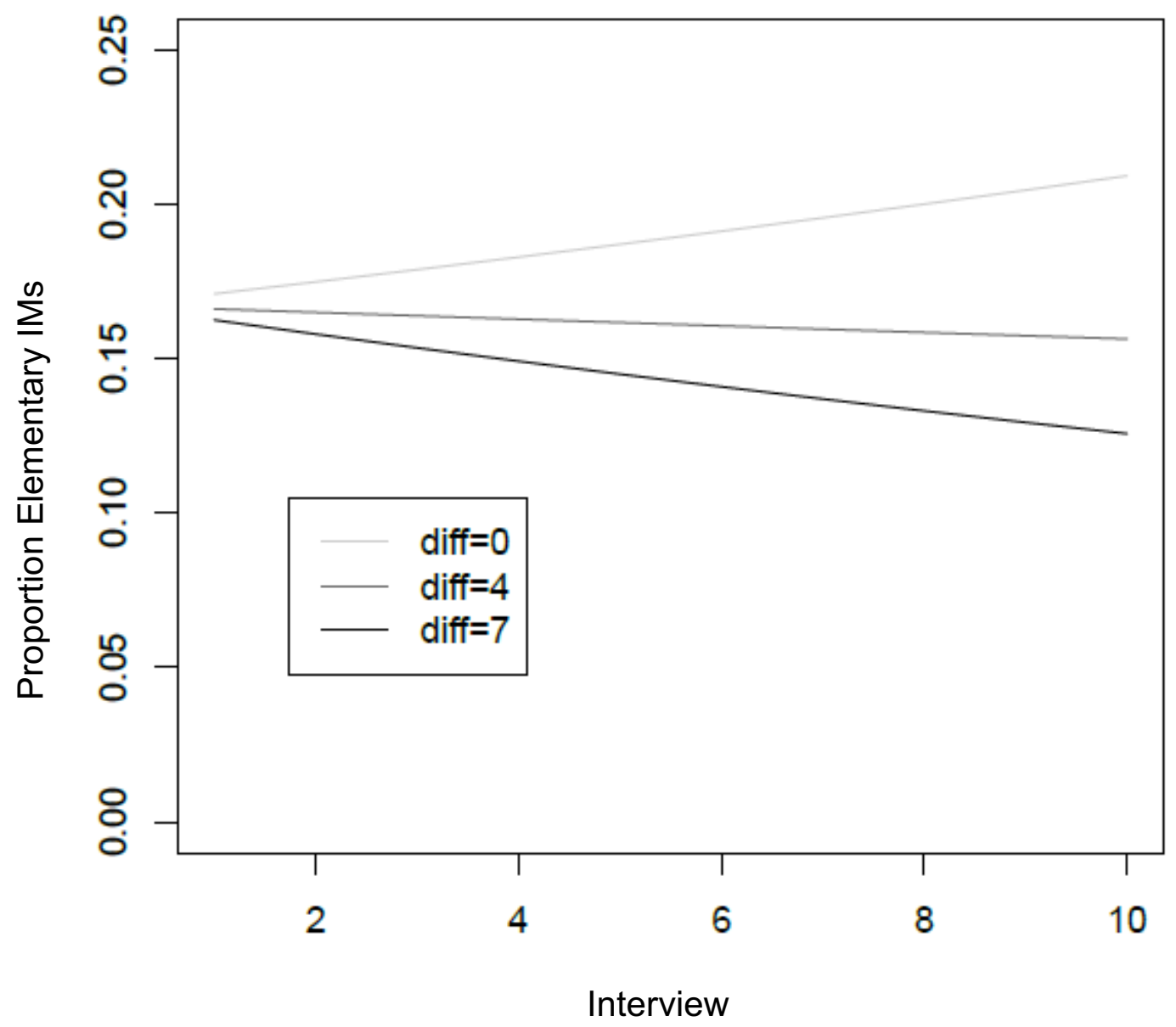

Figure 1. Proportion of elementary IMs. The different gradient lines represent the evolution of the elementary IMs probabilities between two participants with extreme differences in levels of change [P9 (diff = 0), P5 (diff = 7)], and two participants with intermediate levels of change [P3 and P10 (diff $=4)]$. 


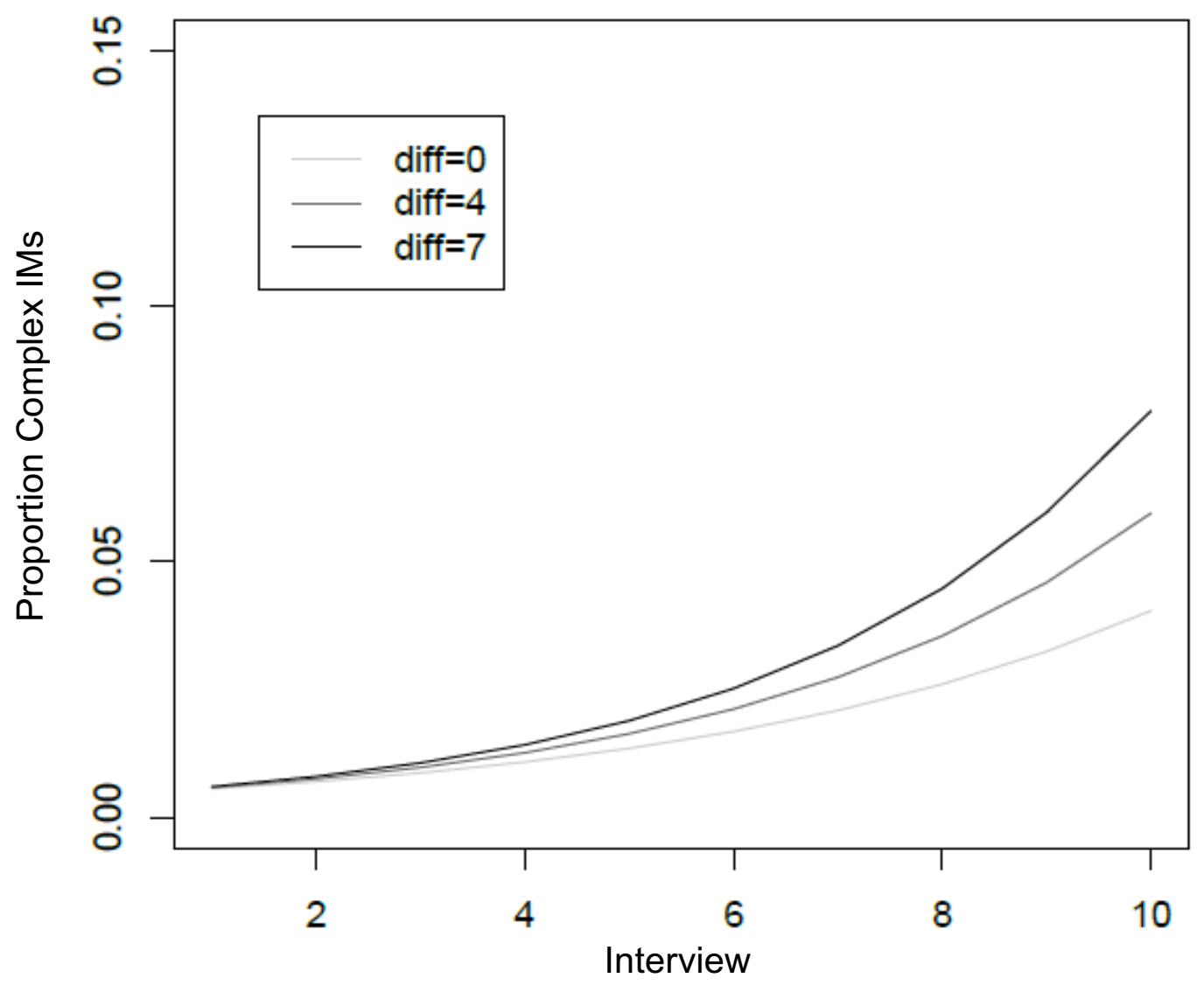

Figure 2. Proportion of complex IMs. The different gradient lines represent the evolution of complex IMs probabilities between two participants with extreme differences in levels of change [P9 (diff =0), P5 (diff = 7)], and two participants with intermediate levels of change $[\mathrm{P} 3$ and P10 $(\operatorname{diff}=4)]$. 